\title{
Effectiveness of Validation Therapy on Level of Cognition Among old Age in Selected Old Age Home, Chennai
}

\author{
V. Hemavathy, M.SC, M. Phil (Nursing) ${ }^{1}$, K. Muthamizh Selvan ${ }^{2}$ \\ ${ }^{1}$ Principal and Professor, Sree Balaji College of Nursing , Bharat University, Chennai, India \\ ${ }^{2}$ II nd Year M.Sc Nursing ,Sree Balaji College of Nursing, Bharat University, Chennai, India
}

\begin{abstract}
Background of the Study: Aging is an inevitable developmental phenomenon bringing along a number of changes in the physical, psychological, hormonal and social conditions. Old age is considered as a risk period because they need assistance for most of their day to day activities, When all the young members of the family are busy in their discourses of life, old people lack the love and attention they need. All these factors contribute in decreasing cognition level in old age .Objectives: To assess the pretest and posttest level of cognition among old age in the experimental and control group, To evaluate the effectiveness of validation therapy on level of cognition among old age in experimental and control group, To associate the level of cognition among old age with their selected demographic variables in experimental group. Hypothesis: There will be a significant difference between the post test score of cognition in experimental and control group among old age. There will be a significant association between the post test level of cognition among old age and their selected demographic variables in experimental group among old age. Methodology: Nonequivalent control group pretest and post-test design was used for this study. Purposive sampling technique was used for the study. Final Result and Conclusion: In the pretest the level of cognition among selected 30 samples in experimental group 2(6.6\%) Of them had normal level of cognition and $\mathbf{6}(20 \%)$ of them had mild level of cognition and 18(60\%) had moderate level of cognition and 4(13.4) had severe level of cognition. In the post test level of cognition among selected 30 samples in experimental group 6(20\%) had normal level of cognition, 12(40\%) had mild level of cognition, $9(30 \%)$ had moderate level of cognition $3(10 \%)$ had severe level of cognition. The effectiveness of validation therapy on level of cognition among old age using paired " $t$ " test shows 20.1 significant at the level of $P<0.001$ which implyi ng that there was significant increasing in the level of cognition among old age people in the post test
\end{abstract}

Keywords: effectiveness, validation therapy, old age, old age home

\section{Introduction}

Cognition refers to the mental process of comprehension, judgment, memory and reasoning in contrast to emotional and volitional process. It includes attention, remembering, producing and understanding language, solving problems, and making decisions. Cognition is studied in various disciplines such as psychology, philosophy, linguistics, and computer science (Lalitha, 2012)

Validation therapy is defined as the use of a method of therapeutic communication with elderly persons that focuses on emotional rather than factual content. It was developed by (NAOMI FEIL) between the year 1963 and 1980 for older people with cognitive impairment. Mainly it is based on the principle of validation, the acceptance of the reality. Feil's own approach classifies individuals with cognitive impairment as having one of four stages in a continuum of dementia. These stages are: Mal orientation, Time confusion, Repetitive motion, Vegetative state (NAOMI FEIL 1963)

\section{Objectives}

- To assess the pretest and posttest level of cognition among old age in the experimental and control group.

- To evaluate the effectiveness of validation therapy on level of cognition among old age in experimental and control group .
- To associate the level of cognition among old age with their selected demographic variables in experimental group.

\section{Hypothesis}

H1 There will be a significant difference between the post test score of cognition in experimental and control group among old age.

$\mathrm{H} 2$ There will be a significant association between the post level of cognition among old age and their selected demographic variables in experimental group among old age

\section{Methodology}

Quasi experimental Nonequivalent control group pre-test and post-test design was selected for this study in Idhaya vaasal elders Home, pallikaranai, Chennai. The study population will comprise of old age people in the age group of (55-70 above) years. Total sample size 60 both male and female old age people are selected for the study by Purposive sampling technique. The questionnaire has 2 parts consisting of Demographic variables these are age ,sex, marital status, religion, education status, marital status, financial support, mode of entry, duration of stay in old age home, second part of questionnaire, mini mental state examination(MMSE) or (FOLSTEIN) test is a 30 point questionnarie was used .Interpretation of score was done as follow. 


\section{International Journal of Science and Research (IJSR) ISSN (Online): 2319-7064}

Index Copernicus Value (2013): 6.14 | Impact Factor (2015): 6.391

\begin{tabular}{|c|c|}
\hline \multicolumn{2}{|c|}{ Table 1} \\
\hline Category & Score \\
\hline Normal cognition & $24-30$ \\
\hline Mild cognition & $20-23$ \\
\hline Moderate cognition & $10-19$ \\
\hline Severe cognition & $0-9$ \\
\hline
\end{tabular}

\section{Result}

Table 2: Pre test level of cognition among old age people

\begin{tabular}{|c|c|c|c|c|}
\hline $\begin{array}{c}\text { Pretest level of } \\
\text { cognition }\end{array}$ & \multicolumn{2}{|c|}{ Experimental Group } & \multicolumn{2}{|c|}{ Control Group } \\
\cline { 2 - 5 } & No & Percentage (\%) & No & Percentage (\%) \\
\hline Normal cognition & 2 & 6.6 & 3 & 10 \\
\hline Mild cognition & 6 & 20 & 7 & 23.4 \\
\hline Moderate cognition & 18 & 60 & 17 & 56.6 \\
\hline Severe cognition & 4 & 13.4 & 3 & 10 \\
\hline Total & 30 & 100 & 30 & 100 \\
\hline
\end{tabular}

Table 2 Reveals the pre test scores of both experimental \& control group. Among the experimental group (6.6\%) experienced normal level of cognition, (60\%) experienced moderate level of cognition and (13.4\%) experienced severe level of cognition. In control group majority of the samples experienced moderate level of cognition (56.6\%) and (23.4\%) experienced mild level of cognition.

Table 3: Post test level of cognition among old age people

\begin{tabular}{|c|c|c|c|c|}
\hline $\begin{array}{c}\text { Post test level of } \\
\text { cognition }\end{array}$ & Experimental Group & \multicolumn{2}{|c|}{ Control Group } \\
\cline { 2 - 5 } & No & Percentage (\%) & No & Percentage (\%) \\
\hline Normal cognition & 6 & 20 & 2 & 6.6 \\
\hline Mild cognition & 12 & 40 & 8 & 26.6 \\
\hline Moderate cognition & 9 & 30 & 17 & 56.6 \\
\hline Severe cognition & 3 & 10 & 3 & 10 \\
\hline Total & 30 & 100 & 30 & 100 \\
\hline
\end{tabular}

In the post test majority of the samples experienced 12 out of 30 samples experienced mild level of cognition (40\%), 6 out of 30 experienced normal level of cognition(20\%), 3 out of 30 experienced severe level of cognition(10\%), and In control group 2 out of 30 experienced normal level of cognition(6.6\%) , 17 out of 30 experienced moderate level of cognition(56.6\%) and 3 out of 30 experienced severe level of cognition(10\%) .

Table 4: Comparison of pre test and post test Level of cognition among old age people

\begin{tabular}{|c|c|c|c|c|c|c|c|c|}
\hline \multirow{2}{*}{ Level of cognition } & \multicolumn{6}{|c|}{ Experimental group n=30 } & \multicolumn{3}{|c|}{ Control group n=30 } \\
\cline { 2 - 10 } & \multicolumn{2}{|c|}{ Pre test } & \multicolumn{2}{c|}{ Post test } & \multicolumn{2}{|c|}{ Pre test } & \multicolumn{2}{c|}{ Post test } \\
\cline { 2 - 10 } & $\mathrm{F}$ & $\%$ & $\mathrm{~F}$ & $\%$ & $\mathrm{~F}$ & $\%$ & $\mathrm{~F}$ & $\%$ \\
\hline Normal cognition & 2 & 6.6 & 6 & 20 & 3 & 10 & 2 & 6.6 \\
\hline Mild cognition & 6 & 20 & 12 & 40 & 7 & 23.4 & 8 & 26.6 \\
\hline Moderate cognition & 18 & 60 & 9 & 30 & 17 & 56.6 & 17 & 56.6 \\
\hline Severe cognition & 4 & 13.4 & 3 & 10 & 3 & 10 & 3 & 10 \\
\hline Total & 30 & 100 & 30 & 100 & 30 & 100 & 30 & 100 \\
\hline
\end{tabular}

Table 4; depicts the pre test\& post test scores of both experimental \& control group. Among the experimental group in pre test (6.6\%) experienced normal level of cognition, (60\%) experienced moderate level of cognition and $(13.4 \%)$ experienced severe level of cognition. But in the post test majority of the samples experienced mild level of cognition (40\%), 6 out of 30 experienced normal level of cognition(20\%), 9 out of 30 experienced moderate level of

cognition(30\%) and 3 out of 30experienced severe level of cognition. In control group in the pre test, majority of the samples experienced moderate level of cognition (56.6\%) 3 out of 30 (10\%) experienced normal level of cognition and post test of control group is 2 out of 30 experienced normal level of cognition( $6.6 \%$ ), the effectiveness of validation therapy among old age people in cognition level, mean score in experimental group was 19.2 in the pre -test, SD was 6.4 and the mean score in experimental group post -test score was 15.9 and SD was 5.6 , so the mean difference was 3.3 with the paired t- test value is 20.1 and there is significant effectiveness at $\mathrm{P}$ value $<0.001$.

\section{Major Findings of the Study}

The study reveals that in experimental group 4(13.3\%) of the samples were in the age group of 55-59 years, $7(23.3 \%)$ of samples belonged to the age group of $60-64$ years, $8(26.7 \%)$ belonged to age group 65-69 years and the majority $11(36.7 \%)$ of samples belonged to the age group of 70 and above years. In the control group 5(16.7\%) of the samples were in the age group of 55-59 years $9(30 \%)$ of samples belonged to the age group of $60-64$ years, $7(23.3 \%)$ belonged to age group 65-69 years and the majority 9(30\%) of samples belonged to the age group of 70 and above years.

Regarding the gender status $17(56.7 \%)$ of the samples were male and $13(43.3 \%)$ of the samples were female in the experimental group. In the control group 18(60\%) of the samples were male and $12(40 \%)$ of the samples were female.

Regarding marital status $15(50 \%)$ of the samples were married, 3(10\%) of the samples are unmarried, $5(16.7 \%)$ of the samples were divorced and $7(23.3 \%)$ of the samples were widow/widower in the experimental group. In the control group $11(36.7 \%)$ of the samples were married, $4(13.3 \%)$ of the samples are unmarried, $6(20 \%)$ of the samples were divorced and $9(30 \%)$ of the samples were widow/widower

In both the experimental group 29(96.7\%) and control group 28(93.3\%) majority of the patients are Hindu by religion, educational status, $6(20 \%)$ of the samples were Illiterate, $6(20 \%)$ of the samples had primary education, $12(40 \%)$ of the samples had secondary education and 1(3.3\%) of the samples were graduates in the experimental group. In the control group, $7(23.3 \%)$ of the samples were Illiterate, $6(20 \%)$ of the samples had primary education, $11(36.7 \%)$ of the samples had secondary education and 2(6.7\%) of the samples were graduates.

Regarding support system, in the experimental group $15(50 \%)$ of the samples were supported by their family, $9(30 \%)$ of the samples were supported by their friends and $6(20 \%)$ of the samples were supported by their others. In the control group $16(53.3 \%)$ of the samples were supported by their family, $8(26.7 \%)$ of the samples were supported by their friends and $6(20 \%)$ of the samples were supported by their others.

Regarding duration of stays, $4(13.3 \%)$ of the samples had been staying for $<1$ year, 11 (36.7\%) of the samples had 


\section{International Journal of Science and Research (IJSR) \\ ISSN (Online): 2319-7064 \\ Index Copernicus Value (2013): 6.14 | Impact Factor (2015): 6.391}

been staying for 1-2 years, 15(50\%) of the samples had been staying for $>2$ years in the experimental group. In the control group $6(20 \%)$ of the samples had been staying for $<1$ year, $13(43.3 \%)$ of the samples had been staying for 1-2 years, and $11(36.7 \%)$ of the samples had been staying for $>2$ years. With mode of entry, in the experimental group, 9(30\%) were voluntary and $21(70 \%)$ were by force. In the control, $11(36.7 \%)$ were voluntary and $19(63.3 \%)$ were by force.

The pre test\& post test scores of both experimental \& control group were tabulated and revealed that among the experimental group 2(6.7\%) experienced normal level of cognition and a majority 18(60\%) experienced moderate level of cognition in the pre test. But in the post test $6(20 \%)$ of the samples experienced normal level of cognition and $9(30 \%)$ experienced moderate level of cognition. In the control group 3(10\%) experienced normal level of cognition and $17(56.6 \%)$ experienced moderate level of cognition in the pre test. But there was mild change in the post test score as $2(6.6 \%)$ experienced normal level of cognition and $17(56.6 \%)$ experienced moderate level of cognition.

\section{Conclusion}

The study reveals that there was significant difference (improving) in the level of cognition among old age people in the post test. The effectiveness of validation therapy among old age people using paired "t" test shows 20.1 significant at the level of $\mathrm{P}<0.001$ in experimental group and paired " $\mathrm{t}$ " test showed 3.1 in control group significant at the level of $\mathrm{P}<0.001$.

\section{References}

[1] Bhatia, M.S. (2007), Text Book of Psychiatry, (3 ${ }^{\text {rd }}$ edition). New Delhi: C.B.S Publishers and Distributors.

[2] Burns Nancy and Susan K.Grove, (2014), The Practice of Nursing Research Conduct-Crialle and Utilization, ( $5^{\text {th }}$ edition). Philadelphia: W.B sunders company publishers.

[3] Dana worchel. (2010), Text Book on Suicide Assessment and Treatment, ( $1^{\text {st }}$ edition). New Delhi: Springer's company publication.

[4] Gail,W, Michele, T et.al., (2015), Principles and practice of psychiatric nursing, $\left(8^{\text {th }}\right.$ edition). Missouri: Mosby Publication.

[5] Katherine,M. Fortinash, et.al, (2006), Psychiatric Mental Health Nursing, ( $1^{\text {st }}$ edition). New York: Mosby publication.

[6] Kaplan and sadock's, (2008), Synopsis is psychiatry ( $8^{\text {th }}$ edition) New Delhi: New B.L. WaverkyPvt.Ltd.

[7] Lalitha, K., (2012), Mental Health and Psychiatric Nursing-an Indian perspective, ( $2^{\text {nd }}$ edition). Bangalore: V.M.G. Book Publishers.

\section{Journal References}

[8] Hebinski, M. et al. (2010) "Finish geriatric intervention study to prevent cognitive impairment and disability." Journal of Geriatric Psychiatry. 25(5).58-62.

[9] Fine, K. \& Rouse Bane, N. (1995), "Using Validation Techniques to Improve Communication with
Cognitively Impaired Older Adults," Journal of Gerontological Nursing, 21(5), 39-45.

[10]Feil, M. (2001), "The effectiveness of validation therapy in dementia- A Pilot Study", International Journal of Geriatric Psychiatry. 32(6). 327-330.

[11]Babins, K. et al. (2013), Validation Therapy, International Journal of Aging \& Human Development, 26, 161-168.

[12] Bleathman, M. Christine, M. B. \& Morton, N. (2010), "Validation method: extracts from 20 groups with dementia sufferers". Journal of Advanced Nursing 17,658-666.

\section{Net References}

[13] http/www.intelihealth.com

[14] http/www.learnwell.og/relax.htm

[15] http/www.pubmed.com

[16] http://www heartquotes.com

[17] http://www.eric.ed.gov 